
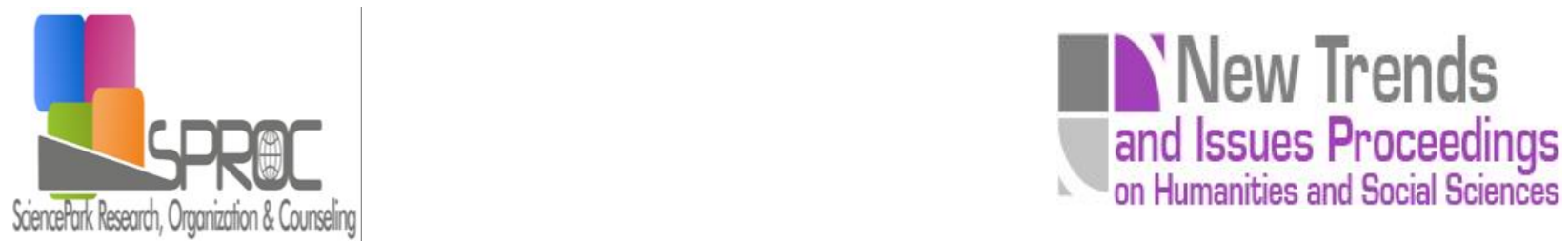

$\underline{\text { www.prosoc.eu }}$

\title{
"COUCHING" PRODUCTS AT KAHRAMANMARAS MUSEUM
}

Nursel Baykasoglua,

H. Feriha Akpinarli ${ }^{b}$

Suggested Citation:

Abstract 
1. Introduction 
2. Technical Features of Couching and The Products in The Museum Of Kahramanmaras

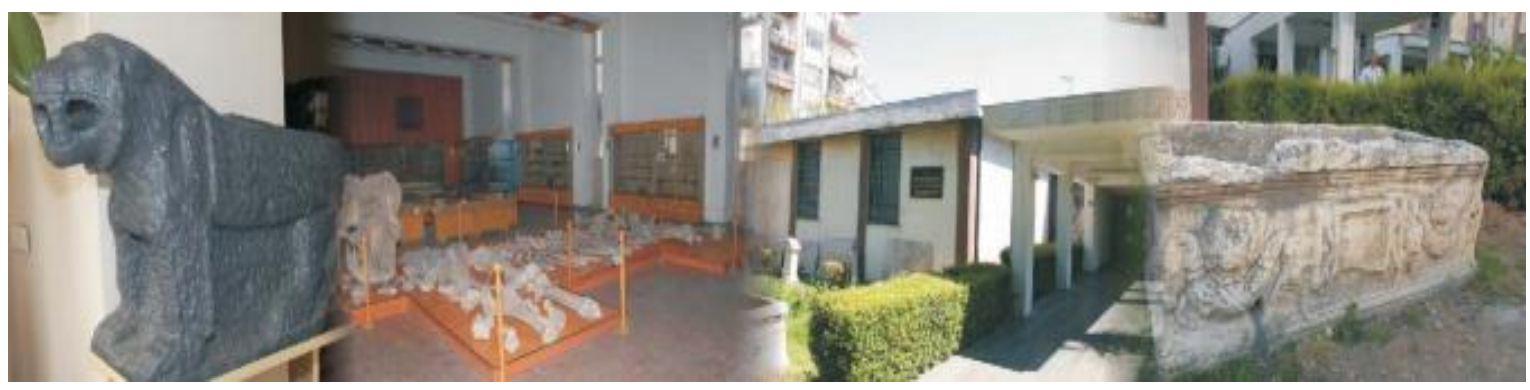

Images . 1 and 2 Kahramanmaraş Museum 

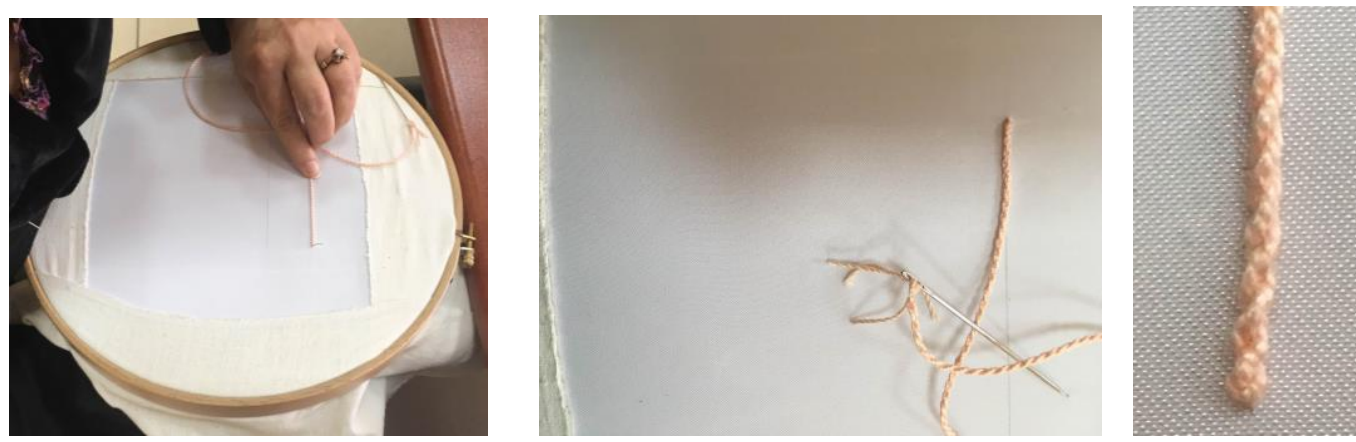

Figure 2. Closed Style Couching
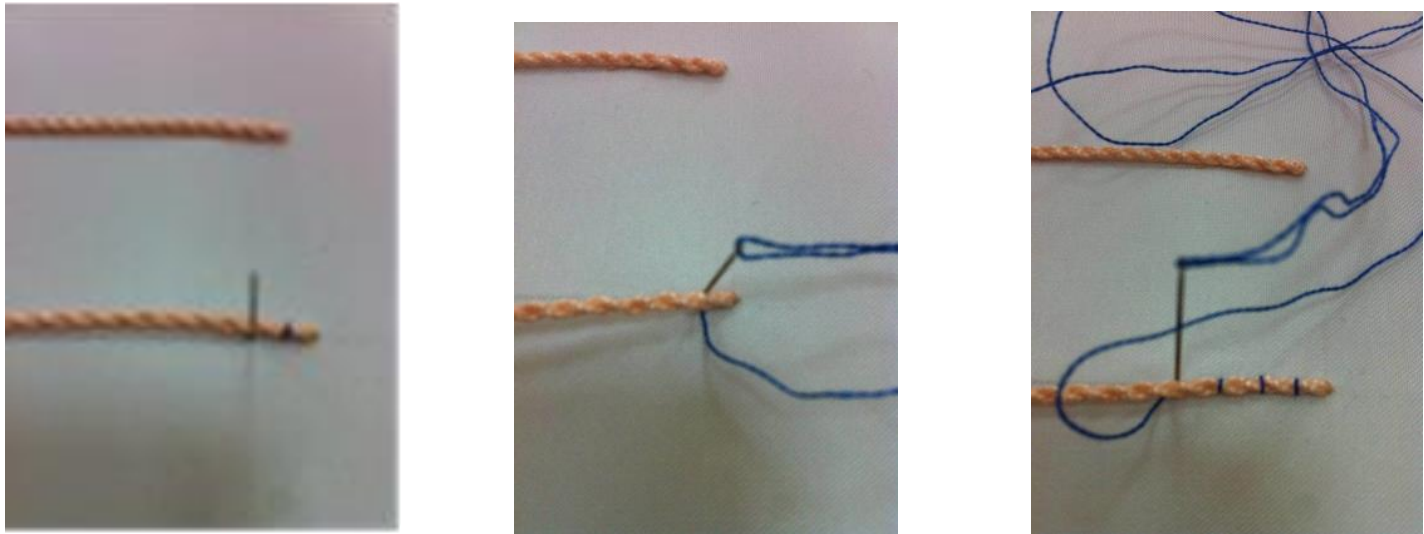

Figure 3. Open Style Couching 

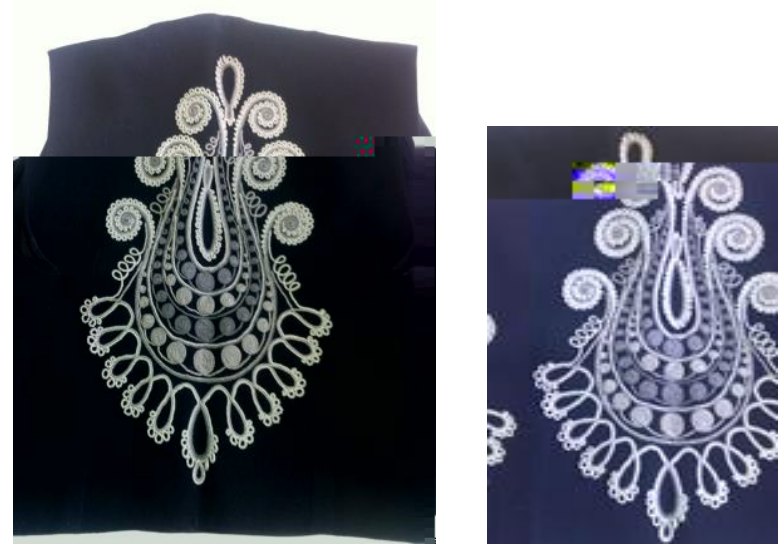

Figure 3. A Vest Worked by Nursel Baykasogu with Couching Technique

References
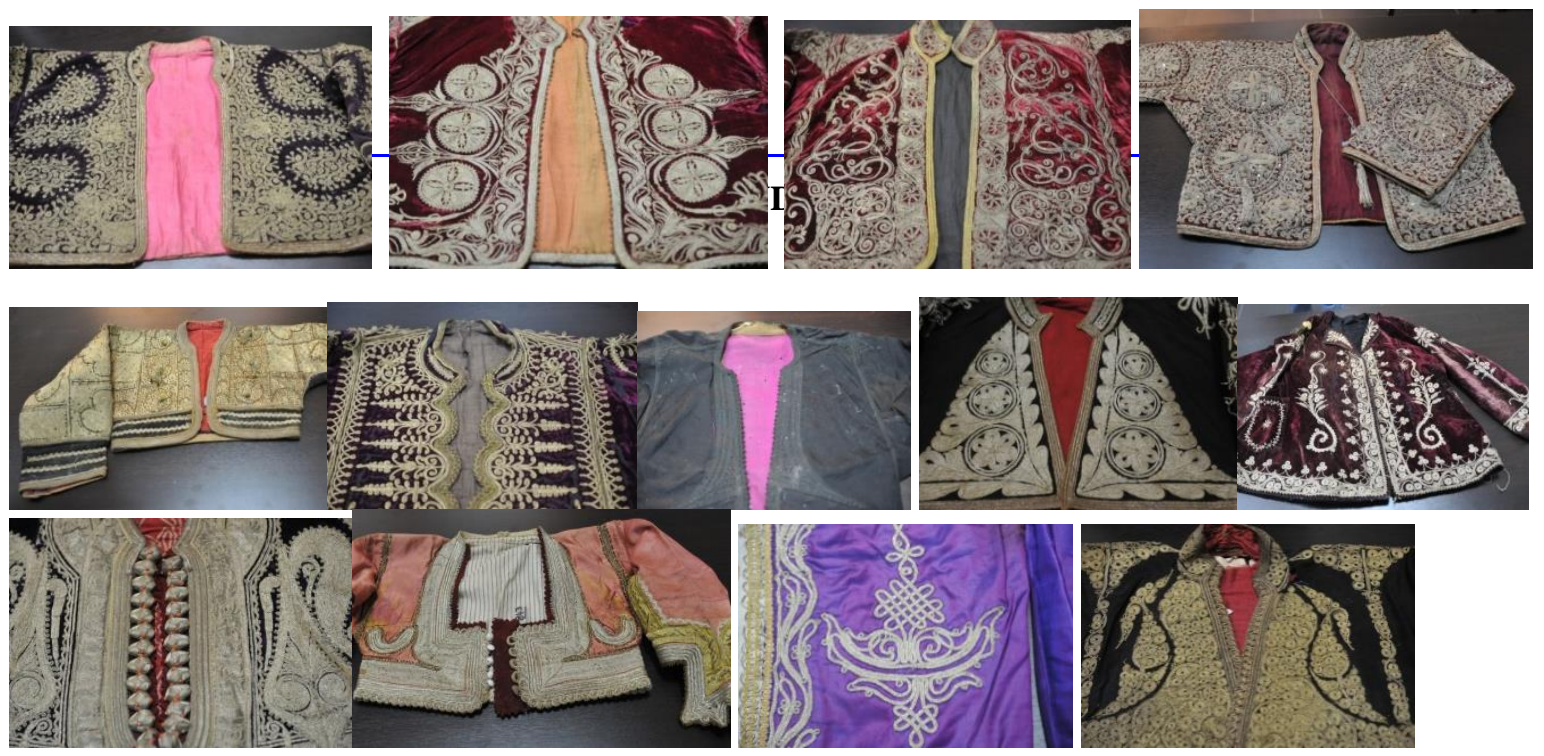

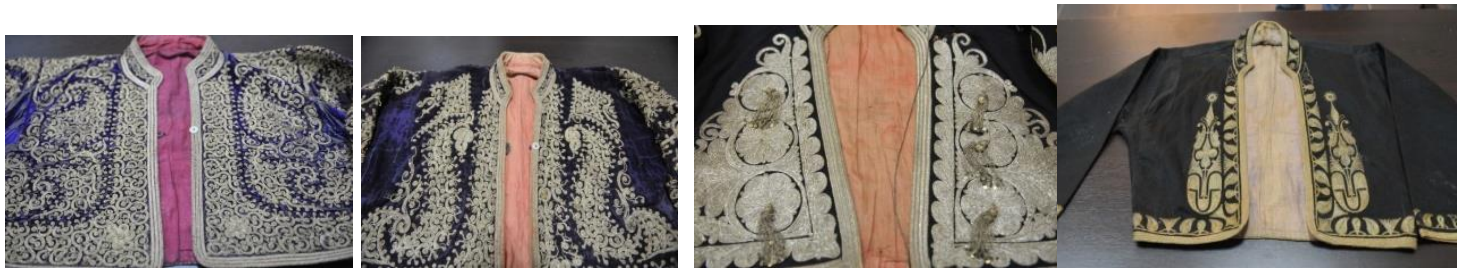

VESTS
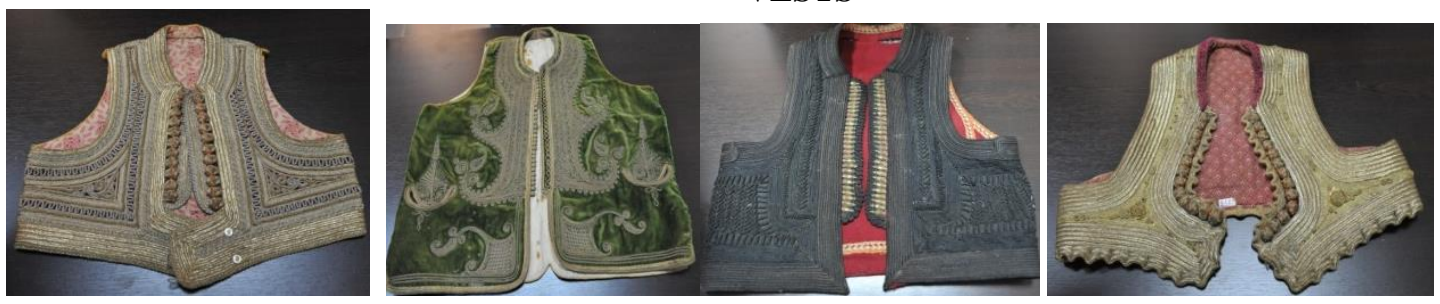

SHALWARS AND SLEEVES
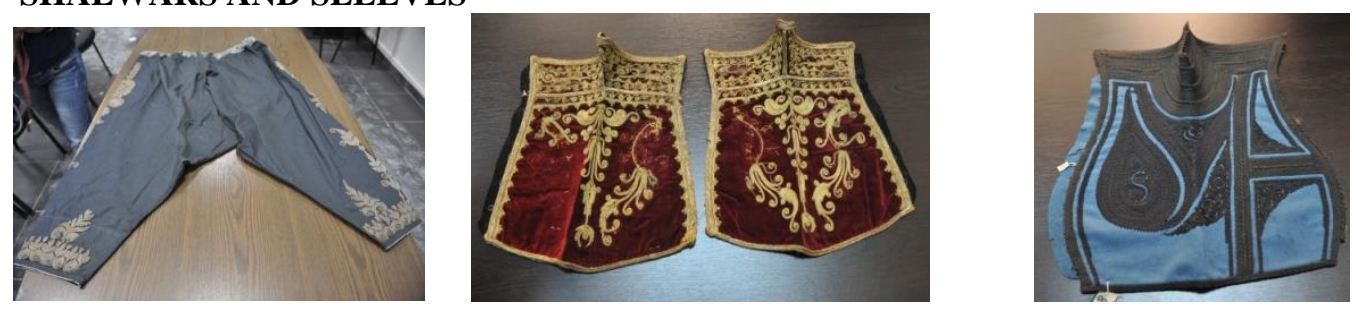